Viewpoint

\title{
Challenges and the way forward in China's new-type urbanization
}

\author{
Mingxing Chen*, Weidong Liu, Dadao Lu \\ Key Laboratory of Regional Sustainable Development Modeling, Institute of Geographic Sciences and Natural Resources Research, CAS, Beijing, China
}

\section{A R T I C L E I N F O}

\section{Article history:}

Received 25 November 2014

Received in revised form 18 July 2015

Accepted 21 July 2015

Available online 31 July 2015

\section{Keywords:}

New-type urbanization

Citizenization

Land-centered urbanization

People-oriented urbanization

Challenges

Way forward

China

\begin{abstract}
A B S T R A C T
China's urbanization has been a notable global event. The National New Urbanization Plan (2014-2020) unveiled by the Chinese Central Government revealed a new path for urbanization that accommodated unique Chinese characteristics. The most notable aspect was the transfer from land-centered urbanization to people-oriented urbanization. Given that land urbanization was the key to the previous orbit, this manuscript aims to analyze the evolution and challenge for land-centered urbanization, and way forward for people-oriented urbanization in China. With increasing urban populations and expanding industrial activities, China has experienced vigorous land urbanization and an uneven population distribution pattern since 1978. Land-centered urbanization has created some economic and social benefits, but has also posed many adverse impacts. The issues of the loss of arable land, the phenomenon of "ghost cities," and the urban heat island effect have become critical challenges. Eight suggestions from two perspectives are recommended in this manuscript for achieving new-type urbanization in China. We should give priority to this issue of the citizenization of peasant migrants. Government, scientists, and the public can all combine to influence the development trajectories of China's new-type urbanization.
\end{abstract}

(C) 2015 Elsevier Ltd. All rights reserved.
China's urbanization has been a momentous event that has attracted wide international attention (Yang, 2013). In March 2014, the Central Committee of the Communist Party of China (CPC) and the State Council jointly released a "National New-type urbanization Plan (2014-2020)" (Zhu, 2014). This was the first official plan to regard new-type urbanization as a national policy, and it pinpointed the problems that had emerged in the previous accelerated urbanization mode; this plan is expected to explore a new path toward sustainable urbanization. The most notable aspect is the transfer from land-centered urbanization (Long, 2014) to peopleoriented urbanization. Given that land urbanization was key to the previous target, greater clarification is needed on the size, growth, distribution, and challenges in China.

\section{China's land urbanization in the past three decades}

Fig. 1 provides a timeline of China's land urbanization trends from 1981 to 2012 . The main features can be summarized as follows: (i) China's rapid economic growth and dramatic urbanization process since its reform and opening-up brought immense urban land expansion. The total urban built-up land area expanded by $513 \%$, from $7438 \mathrm{~km}^{2}$ to $45566 \mathrm{~km}^{2}$, and the annual rate of increase

\footnotetext{
* Corresponding author.

E-mail address: chenmx@igsnrr.ac.cn (M. Chen).
}

reached 6\% between 1981 and 2012; (ii) the urban built-up land area has grown faster than its urban population, and the increase has been particularly rapid since 2000 , which implies that urban population density has been declining for the past 30 years, especially in recent years; (iii) the number of cities had reached 657 by the end of 2012, an increase of 431 compared to 1981 (NBSC, 2013). However, the growth rate was not identical between the two different periods. The salient turning point occurred around 1996, prior to which the number of cities had been rapidly increasing. Since 1996, the number of cities has remained roughly stable.

\subsection{Urban agglomeration}

In recent years, many emerging urban agglomerations, built with an increasing competitiveness, have expanded. In 2012, the total urban built-up land area of 22 urban agglomerates was 32 $192 \mathrm{~km}^{2}$, accounting for $71 \%$ of China's total urban built-up land area; however, the share of the total land area of these urban agglomerates, compared to the whole of China, was only about $22 \%$. The three biggest urban agglomerates are Beijing-Tianjin-Hebei, the Yangtze Delta, and the Pearl River Delta. According to the "National New-type urbanization Plan," urban agglomerates in China will be developed as the main type of new-type urbanization in coming years. 


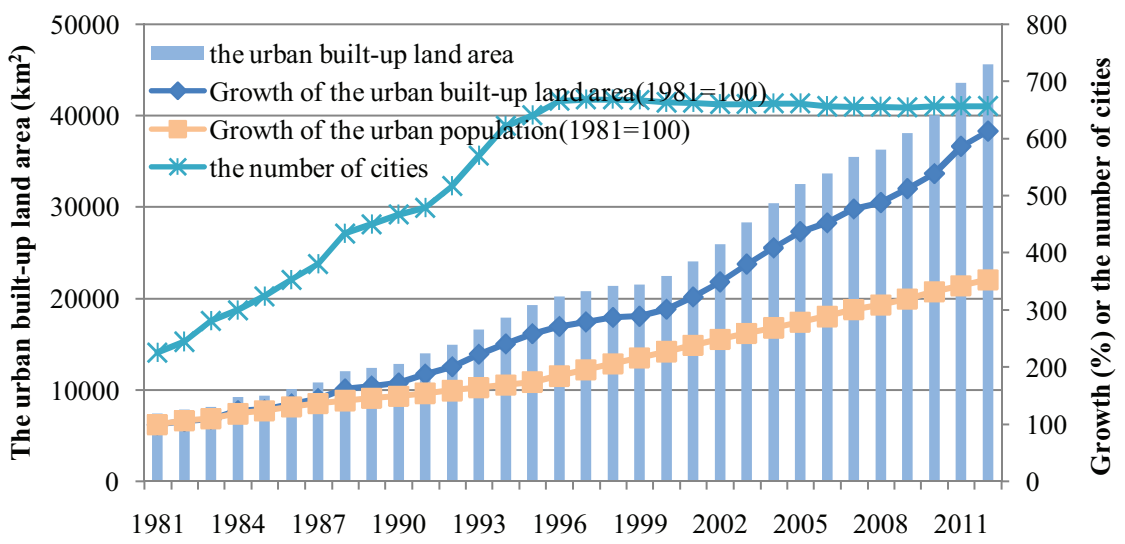

Fig. 1. Land-centered urbanization in the last three decades (NBSC, 2013)

\subsection{Rank-size distribution}

Lorenz curves were used to measure the inequality in the rank-size distribution of urban built-up land area. Fig. 3a shows a cumulative percentage curve of urban built-up land area on the vertical axis plotted against the cumulative percentages of the number of cities by rank size on the horizontal axis. The $45^{\circ}$ line represents a perfect size equality of urban construction land in different cities. As shown by the features of the curves, the spatial distribution of urban built-up land area demonstrates inequality. The cumulative proportions of construction area in urban areas are 50\%, 63\%, 79\%, and $89 \%$ at $11 \%, 20 \%, 40 \%$, and $60 \%$ of the cumulative proportions of number of cities, respectively.

\subsection{Four economic regions}

China can be divided into four regions based on economic management systems: the East, the Northeast, the Central, and the West (Fig. 2 in Long et al., 2010, page 462). The East coast is a booming region with the fastest and highest rate of urbanization; it is also the most economically developed. Fig. 3b confirms that it is the most developed region of China, comprising $46 \%$ of the country's urban built-up land area, with $9 \%$ of the overall land. The Central and the West regions both accounted for 21\% of China's urban area in 2012. The share of the Northeast was the smallest, at $12 \%$.

\section{Challenges facing China's vigorous urban sprawl expansion}

\subsection{China's vigorous urban expansion is facing three major challenges}

First is the loss of a substantial amount of high-quality arable land, leading to risk associated with food security and safety. In 2012, the population of mainland China was 1.36 billion, accounting for $19.1 \%$ of the world total. China, having the world's largest population, and a per capita arable land far below the world average is therefore facing a great challenge of scarcity of arable land (Long et al., 2012). Accelerated urban expansion has further worsened the shortage. Even the strict arable land protection policies (the red line of 1.8 billion mu (a unit of area, 0.0667 hectares) of arable land and the balance of arable land requisition-compensation) aimed at preventing a decrease in the area of arable land, have not affected the growth of urban built-up land (Liu et al., 2014). These policies have had limited success in local implementation, and in some cases, adverse consequences have occurred (Chen, 2007). For example, it is common for high-quality arable land to become occupied and newly reclaimed arable land or inferior quality land to be given as compensation (Zhan You Bu Lie in Chinese). Increasing concern over food security and safety raised by land scarcity and land pollution is expressed in terms of soil availability for agricultural production, which has worsened due to the rapid urban expansion over the past three decades (Bai et al., 2014).

Second is the vigorously growing phenomenon of "ghost cities." Not unexpectedly, some "ghost cities" received a great deal of attention from the media for their empty apartment buildings and magnificent squares. For instance, the Kangbashi district began as a new urban project in Ordos, a wealthy coal-mining city. This area is filled with office towers, government buildings, theaters, new neighborhoods, and sports fields. The district was originally designed to house a million people, yet hardly anyone lives there (Michael, 2014). These "ghost cities" are a result of excessive housing supply and infrastructure construction outpacing the actual needs, along with business speculation on property demand. The emergence of ghost cities is a direct consequence of China's land-centered urbanization. This urbanization mode was rooted in unreasonable evaluation on local government performance based on a single index of local gross domestic product, which in turn resulted in aggressive development, and further induced social injustice and the financial risk of the real estate bubble. The question then became, how to tackle such daunting challenges facing China's current governments?

Third is the overall and continuously increasing influence of urban expansion on the urban heat island (UHI) effect and global warming. With a background of rapid urbanization and population agglomeration, numerous natural environments have been destroyed or modified in the creation of urban areas. Impervious surface area (ISA) is generally defined as any artificial surface resulting from urban development that water cannot penetrate. It includes roads, parking lots, building roofs, and others. The first global ISA spatial distribution at $1 \times 1 \mathrm{~km}$ spatial resolution indicated that China has the largest ISA data in the world (Elvidge et al., 2007). Rapid urban growth is responsible for many environmental changes in the urban environment, and its effects are strongly related to issues of global climate change (DeFries et al., 2010; Chao, 2009). A remarkable phenomenon for urban climates is that the temperatures of urban areas and their surrounding regions are different. The acceleration of urbanization, such as increased ISA and population density, would increase the UHI, which in turn would significantly increase energy consumption and atmospheric pollution (Cocheo et al., 2000) 


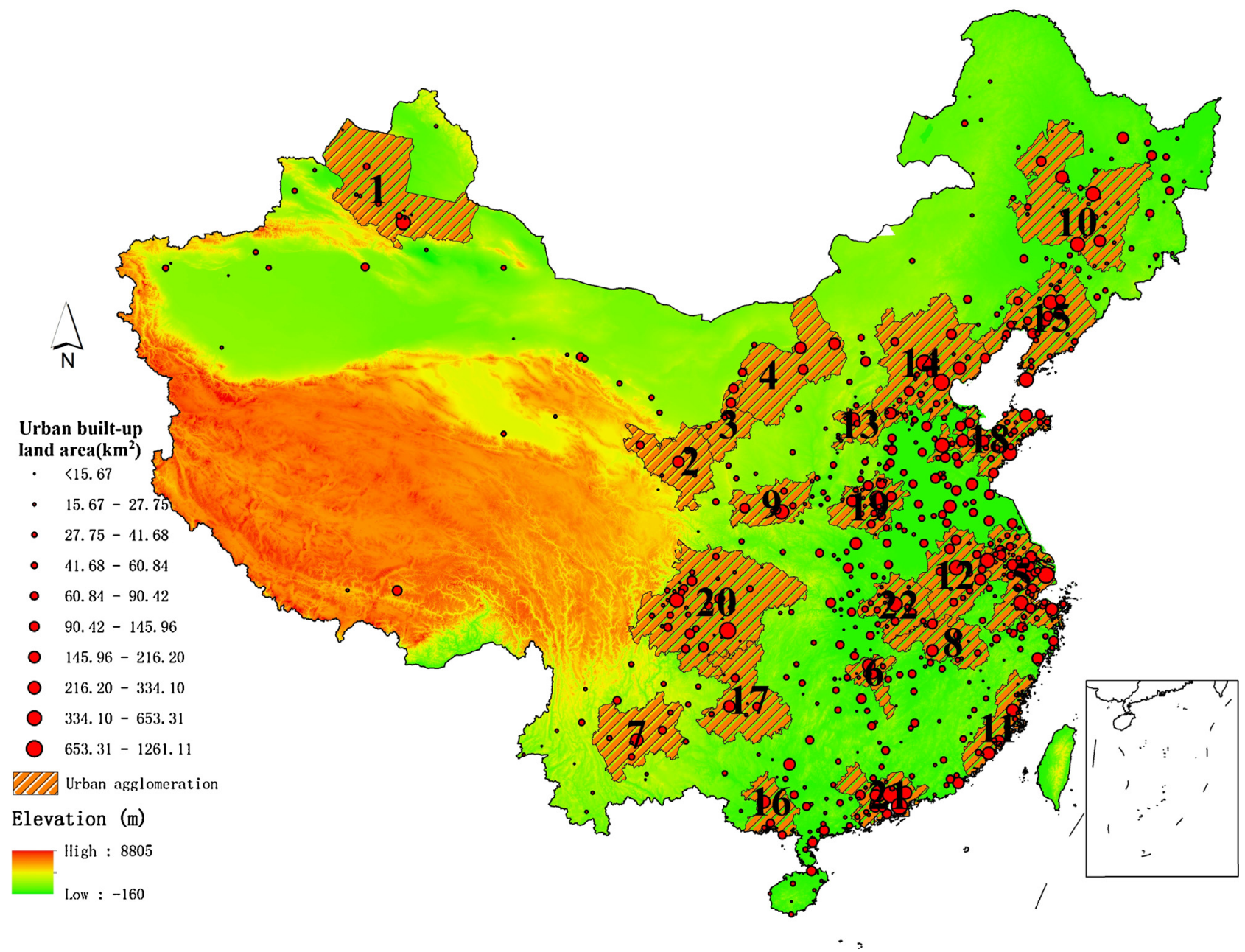

Fig. 2. Distribution of urban built-up land area and urban agglomeration in 2012.

Note: 1, The northern slope of Tianshan Mountains; 2, Lan-Xi-Bai; 3, The Yin Chuan plain; 4, Hu-Bao-E; 5, Yangtze River Delta; 6, Chang-Zhu-Tan; 7, The central of Yunnan; 8, Poyang Lake; 9, Guanzhong Basin; 10, Ha-Da-Chang; 11, The west coast of the Taiwan Straits; 12, Wanjiang; 13, The central of Shanxi; 14, Beijing-Tianjin-Hebei; 15, Liaodong Peninsula; 16, Beibu Gulf; 17, The central of Guizhou; 18, Shandong Peninsula; 19, Central plains; 20, Chengdu-Chongqing; 21, The Pear River Delta; 22, Wuhan.

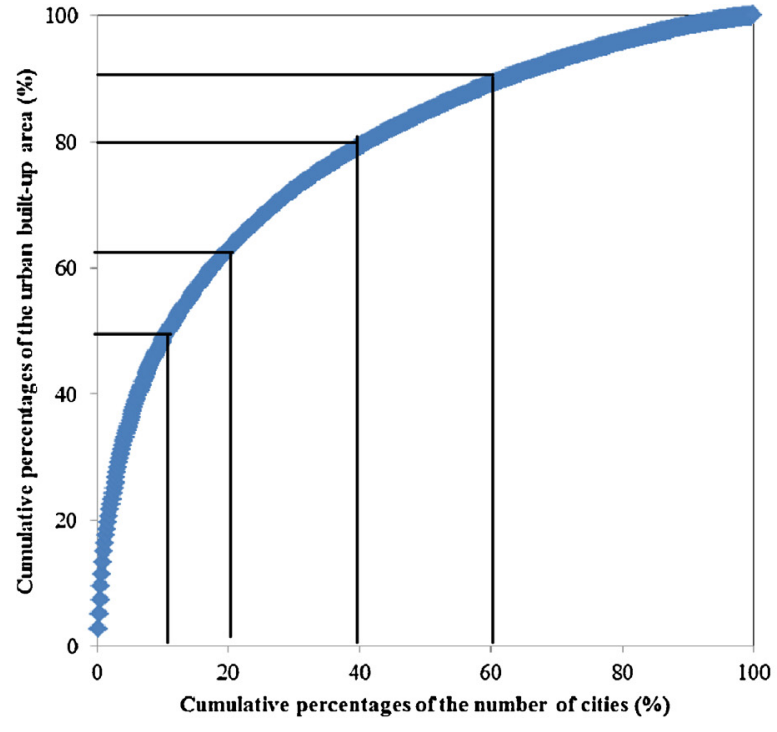

(a)Size distribution

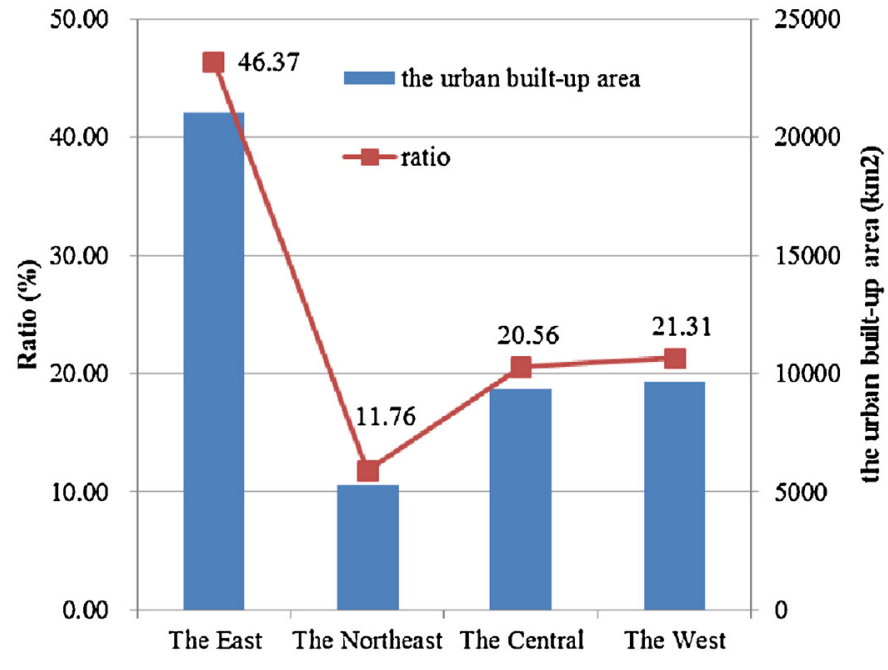

(b) Distribution in four regions

Fig. 3. Size and geographical distribution of urban built-up land area. 


\section{Way forward and future policy considerations for new-type urbanization}

In summary, since its reform and opening-up, China has pursued an accelerated and unbalanced urbanization model (Chen et al., 2013). This has resulted in dramatic land use conversion from agricultural to nonagricultural purposes. Land urbanization in China is not only the outcome of population urbanization but it is also the driver. It is encouraging to see that China's leadership recognized the serious problems emanating from past land urbanization modes. In the context of the National New-type urbanization Plan, the Chinese government firstly admitted the mistake that land urbanization outpaced urban population growth. Urban sprawl, low efficiency in land use, too many new urban districts, large wide roads, and spacious squares are among the problems that China plans to avoid in the future. Although the human-oriented urbanization put forward, the plan, however, had paid too little attention to how to implement them in future. We recommend the following eight suggestions from two perspectives for achieving new-type urbanization in China.

\subsection{Several key tasks that should be mentioned}

\subsubsection{Accelerate the process of the citizenization of peasant migrants}

Promotion of the citizenization of peasant migrants is the primary task for new-type urbanization. Under the past mode of land-centered urbanization, vast numbers of migrant workers were just counted as urban population, but could not generally enjoy basic public services and social security; in other words, they were not given equal rights to the urban population and they were not true citizens. There are two problems with regard to the citizenization of peasant migrants: one is the household registration system (hukou system)(Chan, 2010), the other is economic cost. For the former, the dual-resident systems in rural and urban areas may better not be implemented, and it would be more advisable to extensively implement a policy for peasant migrants to settle in places of work. In practice, small and medium-sized towns can gradually liberalize their resident system, and this could be followed by the megacities. Economic cost is definitely a difficulty for new-type urbanization, so a cost-sharing system in which the central government, local government, enterprises, and individuals all take part is a feasible method we would try to explore. Moreover, subjects and responsibilities should be specifically defined, and the Central Government could encourage and support local governments to promote the citizenization process through policies connected to a city's capacity to absorb migrants, such as financial transfer payments and a constructional land index. From now until 2020, three "100 million people" are placed emphasis on: promote about one hundred million peasant migrants and resident population to settle in cities; transform shantytowns and city villages where about one hundred million people live; guide about one hundred million people to settle in nearby cities in central and western regions.

\subsubsection{Give priority to employment in urban areas}

We had better further implement a strategy of employment priority to promote the development of new urban areas, and to promote a harmonious development of urbanization, industrialization, and agricultural modernization. Existing research had weaken the rationale for, or pursuing, panoramic urbanization or encouraging accelerated urbanization by government-oriented mode as part of a booming economic development in developing countries (Chen et al.,2014a). Instead, increasing the number of off-farm jobs substantially is an urgent but long-term task for us to undertake so as to promote urbanization. More active employment policies can be taken to meet the needs of multi-level employment, and the creation of a more favorable policy for environment and system construction. Employment not only provides jobs, but also an associated stability, a fair income, decent working conditions, a good working environment, and labor rights. Employment encompasses both quantity and quality, and it offers a dignified chance to improve quality of life. In other words, the government can evaluate the quantity of off-farm jobs, the sustainability of the future economy, and the attraction to urbanization, to reasonably determine and control the speed, scale, and spatial distribution of local urbanization. In addition, strengthening skills training and vocational education would improve the quality and ability of peasant migrants in their jobs, and also provide the support of skilled human resources for the new-type urbanization.

\subsubsection{Guide people to cluster or disperse in cities of different scales}

At present, many big cities in China have met the obstacles of environmental degradation, severe traffic congestion, fast-rising housing prices, and urban vulnerability, which have attracted great attention. Entering a period of "big city disease," it is imperative to strengthen the governance in megacities. The "city disease" is mainly derived from the coexistence of insufficient or excessive agglomeration at different city scales during the rapid urbanization process. Megacities, like Beijing and Shanghai, are offered prior opportunity, and consequently, many resources such as fixed asset investment, construction land index, and population flow into these big cities, where there are already over-agglomerations. On the other hand, small and medium-sized towns are facing the problems of population outflow and insufficient agglomeration of resources. Therefore, new-type urbanization will favor optimization of the structure of urban scale, speed up the transformation and upgrade of industries in core cities, extend industries and service chains into hinterlands, and enhance the functions of cities. Small and medium-sized cities are used as the main subjects in optimizing the structure of urban scale, in strengthening the implementation of industrial and public service resources layout, and in improving the vitality of these small cities. Small cities can be given priority, and it must control quantity, improve quality, save land, and promote the coordination of the development of small towns and nearby rural areas.

\subsubsection{Correct urban biased policies, guide urban-rural harmonious development}

"Urban bias" means that urban areas are the center of a country's economic development strategy, and all kinds of national resources focus on urban and industrial development. Under such a policy, governments presume that, in the future, the advanced industry and urban cities will drive the development of agriculture and rural areas. During the urbanization process, "urban bias" is not a result of natural causes but of the politics in China. Through a series of policies, cities gather many resources over a short period of time, and have a prior chance to develop industry for driving economic development; due to this practice, rural areas become forgotten. Consequently, the income difference and level of public services between urban and rural areas become diverse. When facing such a reality, some people believe it is a conscious attempt to eliminate rural areas. In fact, urbanization is a problem of regional development and, regardless of regional characteristics, only considering urban system planning from the perspective of cities is unreasonable. Recent research (Chen et al.,2014b) has demonstrated that, according to the "Northam curve," the upper limit of urbanization is about $80 \%$, which means that the urbanization rate in most countries cannot reach $100 \%$ (i.e., urbanization is not a process of eliminating rural areas, but of reaching a balance). The relationship between urban and rural areas is significant in the process of urbanization, and it requires modern development as well as urban 
historical culture. Under the new-type urbanization process, more attention is supposed to be paid to harmonious urban and rural development, and the construction of new countryside is a valid approach for us to attach great importance to. For this, two key points are imperative: one is to attract talent to join in the construction of new countryside; the other is to narrow the difference in the level of public service between urban and rural areas.

\subsubsection{Establish environmental and resource red lines in urbanization development}

Although people hold different views, it is widely acknowledged that the pressure and damage on resources and environment caused by urbanization are becoming more prominent. In turn, the fact that healthy urbanization is facing restraints on resources and environment is becoming more obvious. As a result, newtype urbanization needs to set red lines for the environment and resources in the process of urbanization. The first one is the land red line and its quality standard. In the future, there would be a strict curb on land acquisition for urbanization and the blind expansion of the real estate market; a firm red line would better be placed at 1.8 billion mu of arable land, to ensure national food security. At the same time, attention should be paid to the combination of city construction land increase and rural residential land decrease, to protect high-quality arable land.

The second is that, based on the environmental capacity, we determine environmental red lines such as those of water or atmosphere; constraint red lines and survival quality red lines should be separated. The former are mainly based on environmental factors, for example, to establish a ratio of urban to rural land in a region, the maximum level of water resource utilization, or acceptable pollution levels, and so on, should be considered. Using these parameters, we can control the urban population, the development of resources, and the economic development scale, such as urban expansion, carrying capacity of water resources, and so on. The latter parameter would determine base line environmental quality in terms of atmosphere, water, and soil, for the support of new-type urbanization. Achievement of these standards will allow people to enjoy clean air, clean and safe drinking water, soil, and so on, to meet basic health guidelines.

The third one is to delimit the necessary ecological red line. This would aim at both national and regional ecological security and economic and social sustainable development, with the target of strictly protecting ecological spaces such as nature reserves, forest parks, etc.

\subsection{Active participation in different groups}

Whether the new-type urbanization can be effectively implemented or not depends on participation of the public. New-type urbanization is not only a government plan or the research subject of scientists, it is also a process for all citizens to participate in.

Initially, people need to realize that livable space and space suitable for urbanization within China are finite; every country in the world has to comply with its own national situation. In China, there are massive regional differences in natural conditions, of which the most important are the three topographical steps and the three natural zones (the eastern monsoon climate zone, the northwestern arid and semi-arid zone, and the Qinghai Tibet cold highland zone) (Lu et al., 2011). Not only do these three topographical and natural zones shape the geography of China's socioeconomic development and urbanization, but also the fact that around 60\% of China's territory comprises mountains and plateaus limits the areas suitable for urbanization, giving rise to the importance of high-density and space-saving urban development. The limited living space and vulnerable eco-environments in China would be unable to sustain another round of growth of extensive urbanization.
Moreover, the developmental ideas and performance evaluation of local government is supposed to be changed. Accelerated land urbanization is not an automatic panacea for all the ills of economic growth. It is inappropriate for decision-makers to set too high a target in advance (Bloom et al., 2008). To achieve sustainable urban development in China, policy makers may not place too much emphasis on the quantity of growth and the growth rate, but mainly focus upon the reform of relevant policies so as to keep abreast of growing urbanization. In this way, they can improve, for example, the granting of urban status to qualified rural workers and the protection of the resource environment, especially high-quality arable land. Meanwhile, a stricter land management system is of great significance for governments to establish. Greater efficiency of land use will require greater compensation for land requisition, and new mechanisms for converting rural construction land to urban uses. In particular, rigorous legal limits would better be established on government natural land requisition.

Finally, for academia, further studies on sustainable urbanization and urban smart growth that carefully integrate multidisciplinary perspectives and approaches are required to continue refining our understanding of the relative importance and complex interplay of population, land, economy, and environment in the urbanization process. Urbanization is a complex issue that must be assessed not only in terms of urbanization speed or effects of economic growth. The future effects of land urbanization will be comprehensively evaluated, taking ecological degradation and environmental sustainability into account. Only when all these facets have been considered can we fully assess the urbanization process (Chen et al., 2014a). Urbaniztion is a new frontier and interdisciplinary field, and it's time to establish an urbanization science (Solecki et al., 2013; Chen, 2015).

Since the release of the National New-tpye Urbanization Plan, China has succeeding in implementing a gradual change. However, urbanization is a comprehensive problem, and we should enhance and unite the understanding of new-type urbanization. This government plan is therefore only the beginning of exploration of new-type urbanization patterns in China; there is still a long way to go.

\section{Acknowledgements}

This research was jointly funded by the Project of National Natural Science Foundation of China (Grant No. 41001080, 41430636, 41125005). We also appreciate the referees for their valuable comments.

\section{References}

Bai, X., Shi, P., Liu, Y., 2014. Realizing China's urban dream. Nature 509, 158-160. Bloom, D.E., Canning, D., Fink, G., 2008. Urbanization and the wealth of nations. Science 319 (5864), 772-775.

Chan, K.W., 2010. The household registration system and migrant labor in China: notes on a debate. Popul. Dev. Rev. 36 (2), 357-364.

Chao, R., 2009. Effects of increased urbanization. Science 324, 37.

Chen, J., 2007. Rapid urbanization in China: a real challenge to soil protection and food security. Catena 69 (1), 1-15.

Chen, M., 2015. Research progress and scientific issues in the field of urbanization. Geog. Res. 34 (4), 614-630 (in Chinese).

Chen, M., Liu, W., Tao, X., 2013. Evolution and assessment on China's urbanization 1960-2010: under-urbanization or over-urbanization? Habitat Int. 38, 25-33.

Chen, M., Zhang, H., Liu, W., Zhang, W., 2014a. The global pattern of urbanization and economic growth: evidence from the last three decades. PLoS One 9 (8), e103799.

Chen, M., Ye, C., Zhou, Y., 2014b. Comments on Mulligan's revisiting the urbanization curve. Cities 41, S54-S56.

Cocheo, V., Sacco, P., Boaretto, C., et al., 2000. Urban benzene and population exposure. Nature 404, 141-142.

DeFries, R.S., Rudel, T., Uriarte, M., Hansen, M., 2010. Deforestation driven by urban population growth and agricultural trade in the twenty-first century. Nat. Geosci. 3 (3), 178-181. 
Elvidge, C.D., Tuttle, B.T., Sutton, P.C., Baugh, K.E., Howard, A.T., Milesi, C., Nemani, R., 2007. Global distribution and density of constructed impervious surfaces. Sensors 7 (9), 1962-1979.

Liu, Y., Fang, F., Li, Y., 2014. Key issues of land use in China and implications for policy making. Land Use Policy 40, 6-12.

Long, H., 2014. Land use policy in China: introduction. Land Use Policy 40, 1-5.

Long, H., Li, Y., Liu, Y., Woods, M., Zou, J., 2012. Accelerated restructuring in rura China fueled by 'increasing vs. decreasing balance'land-use policy for dealing with hollowed villages. Land Use Policy 29 (1), 11-22.

Long, H., Liu, Y., Li, X., Chen, Y., 2010. Building new countryside in China: a geographical perspective. Land Use Policy 27 (2), 457-470.
Lu, D., Fan, J., Liu, W., et al., 2011. China's Regional Space, Function and Development. China Land Press, Beijing (in Chinese).

Michael, C., 2014. Ordos, China: A Modern Ghost Town. Time. http://content.time. com/time/photogallery/029307197539700.html

2013. National Bureau of Statistics of China (NBSC). In: China Statistical Yearbook China Statistics Press, Beijing.

Solecki, W., Seto, K.C., Marcotullio, P.J., 2013. It's time for an urbanization science. Environ. Sci. Policy Sustain. Dev. 55 (1), 12-17.

Yang, X.J., 2013. China's rapid urbanization. Science 342, 310

N. Zhu, Xinhuanet China unveils land-centered urbanization plan 2014; http:// news.xinhuanet.com/english/china/2014-03/16/c_133190495.htm 